\title{
Environmental Sustainability: The Ecological Footprint in West Africa
}

\author{
Sandra T. Marquart-Pyatt \\ Department of Sociology, Environmental Science and Policy Program, \\ Michigan State University, East Lansing, United States
}

\section{Abstract}

\begin{abstract}
Although achieving sustainability remains a key goal of development, efforts to attain it vary across places, making a regional focus important. This paper investigates the ecological footprint - one measure of environmental sustainability - over time with focus on West Africa. Expectations from environmental impact and structural human ecology approaches are incorporated into an investigation of key factors driving national-level environmental sustainability in five countries. Results reveal that demographic attributes are key factors that affect ecological footprints in these countries. Findings are discussed with attention to policy implications regarding the West African context and in relation to opportunities for exploration in further academic study.
\end{abstract}

Keywords: environmental sustainability, West Africa, ecological footprint

\section{Introduction}

Prominent international organizations including the United Nations (UN), United Nations Development Programme (UNDP), Food and Agriculture Organization of the UN (FAO), and the World Bank focus on the importance of the environment for continued development efforts (FAO, 2013; UNDP, 2014; World Bank, 2014, 2015). Ensuring environmental sustainability, for instance, was one of the Millennium Development Goals (MDG) from 2000 to 2015. Although these goals have been reformulated, beginning in 2015 with an eye to transforming development, the environment features prominently in many of these goals, including providing access to clean water and sanitation, maintaining healthy ecosystems, addressing climate change, and improving other aspects of well-being (UNDP, 2014). Questions regarding how to examine spatial and temporal variability in the environment-development link remain core objectives of academic research. This research contributes to this work by examining a measure of environmental sustainability over time with emphasis on five countries in West Africa as context. 
Comparative sociological research examining the processes affecting environmental sustainability seeks to answer the salient question of how much pressure nations exert on their surrounding environment through various industrial processes and related consumptive activities. To date, research demonstrates ecological footprints - a widely used measure of environmental sustainability - to be driven by a variety of economic, political, ecological, and demographic factors at varying - national, regional, and global-scales. An understudied domain of scholarship is that of a specific region over time that also allows for regional heterogeneity (Dietz \& Jorgenson, 2014). The main purpose of this paper is to examine the driving forces of environmental sustainability over time with emphasis on five West African countries as a region and attention to dynamics across different components of ecological footprints with significant within-region implications.

A dataset of five West African countries-Burkina Faso, Ghana, Mali, Niger, and Nigeria-for 46 years (over 224 case years) is used in empirical models integrating expectations from prior work with emphasis on structural human ecology. Countries in dryland West Africa have unique environmental challenges for their cropping systems, and thus for the coupled human and natural systems investigated in this research. Results demonstrate the importance of demographic factors over time in these five nations, although these driving factors do differ to some extent across four of the ecological footprint's subcomponents.

The paper proceeds as follows. The next section describes theoretical frameworks informing this research, with special attention to structural human ecology. The empirical models designed to test expectations from prior research are discussed next, followed by results and discussion of the analyses. The paper concludes with a discussion of avenues for future academic work on macrocomparative, cross-national scholarship on environmental sustainability.

\section{Explaining the factors affecting environmental sustainability}

Developing a better understanding of how human actions lead to environmental change is an essential task for academic research in an increasingly interconnected world. And, as briefly outlined at the outset, such an agenda features prominently in the work of international organizations like the UNDP, FAO, and World Bank. Describing these large-scale processes that span human and natural systems requires an approach that is able to articulate how social structure and institutions both shape and are shaped by the physical environment (Dietz \& Jorgenson, 2013; Liu et al., 2007a, 2007b). As a discipline, sociology, and specifically the subfield of environmental sociology, has made 
important contributions to this work, including our understanding of human activities and aggregate societal characteristics leading to the atmospheric emissions of greenhouse gases (GHG) (Rosa \& Dietz, 2012). Environmental sociologists, therefore, are well equipped to investigate how human activities, social institutions, and relations between social units at numerous scalescommunity, national, regional, and international, for instance-contribute to environmental changes like those portrayed in a measure of environmental sustainability like the ecological footprint.

The essential conceptual background for such investigations derives from models like those of Duncan (1959), Ehrlich and Holdren (1971), and York, Rosa, and Dietz (2003a, 2003b). The shared pillars of these approaches are population, (social) organization, environment and technology, which form the core of Duncan's (1959) POET model. Each of the four domains is posited to play a role in social and environmental change and each has a unique role in the system of relations whereby human societies and the physical environment are involved in an interconnected web of often-reciprocal relations. Ehrlich and Holdren (1971) developed the IPAT model from a similar background, where the Impact is a function of population, affluence and technology. According to this approach, increasing populations interact with changing levels of affluence and technology to yield an environmental impact. The third model, the STIRPAT model (York et al., 2003a, 2003b), has strong ties with both ecological models and uses the same dimensions but in a stochastic form.

To determine how much pressure nations exert on their surrounding environment, sociological scholarship examines a number of aggregate factors as core influences on a measure of environmental sustainability like the ecological footprint. This research draws from a range of theoretical traditions, including ecological modernization, world systems approaches, ecologically unequal exchange frameworks, and world polity perspectives. ${ }^{1}$ Briefly, this scholarship examines economic, political, ecological, and demographic factors as primary drivers of change in environmental conditions. Initial studies in this vein examined society-environment relations as embodied in sociological work on

\footnotetext{
1 Ecologically unequal exchange uses the system of international stratification essential to a world systems perspective (Snyder \& Kick, 1979; Wallerstein, 1979) and investigates the movement of goods across national boundaries (Bunker, 1985; Jorgenson, 2004; Rice, 2007). Examining power imbalances related to environmental space, it focuses on material-ecological exchanges and vertical flows of exports that reinforce existing global inequalities. These flows are intimately tied to environmental degradation. More specifically, exports to wealthier or core nations from poor or peripheral nations increase environmental degradation in some places (Jorgenson, 2004; Rice, 2007). This is especially true in lesser developed countries. Core nations externalize environmental costs related to their consumptive-based lifestyles and industrial production processes onto lesser developed countries (Jorgenson \& Rice, 2005; Rice 2007). In effect, lesser developed countries engaged in greater exports to core nations will differ in levels of resource-intensive consumption compared with other developing nations.
} 
ecological footprints (York, Rosa, \& Dietz, 2003a, 2003b; Jorgenson, 2003, 2005, 2009; Jorgenson \& Burns, 2007a, 2007b; Jorgenson \& Rice, 2005; Rice, 2007; Rice \& Rice, 2009; York, Rosa, \& Dietz, 2009).

More recent work casts a wider net in terms of the potential influences important for sociologists to investigate (Jorgenson \& Clark, 2011; Knight, Rosa, \& Schor, 2013). Economic factors feature prominently in this research. Economic drivers include, for example, the growth of the service sector base, integration into the world economy, degree of export dependence, and national affluence. State environmentalism, democracy, distance from the equator, the degree of urbanization, and population size have also been found to affect national resource consumption as political, ecological, and demographic factors, respectively. From this base of institutional structures, which continues to inform empirical studies, research has broadened to include both measures of militarization with regard to physical size of the military and military expenditures (Jorgenson \& Clark, 2011) and employment (Knight, Rosa, \& Schor, 2013).

Environmental impact theories that include, for instance, ecological modernization, emphasize anthropogenic forces like demographic and economic factors as drivers of environmental change. York et al. (2003a) articulated expectations regarding primary demographic influences on environmental change like population age structure, specifically the size of a country's adult population, and a country's urbanization. With regard to urbanization, some argue that the effects of urbanization may promote less environmentally threatening forms of consumption (Ehrhardt-Martinez, Crenshaw, \& Jenkins, 2002; York et al., 2003a). Regarding economic activity, some argue from a modernization framework that shifting economic base from manufacturing toward service-based economies could reduce impacts on the environment through declines in natural resource extraction (Ehrhardt-Martinez et al., 2002; York et al., 2003a).

Although the focus has shifted slightly, institutional structures continue to inform this scholarship. For instance, along with economic development, international trade regimes, urban population growth, and ecological conditions, research demonstrates that militarization has an effect on national ecological footprints in developing countries (Jorgenson \& Clark, 2011). In addition, research reveals that work hours have a positive effect on national ecological footprints in industrialized or developed nations alongside other economic measures (Knight, Rosa, \& Schor, 2013). In this way, scholarly work considers ecological footprints as consumption-based, national environmental impacts that apply at multiple scales, including nations, regions, and the world; thus, they comprise a major indicator of changing natural environments. 


\section{The importance of structural human ecology}

Structural human ecology (SHE) specifies anthropogenic forces as key drivers of environmental change. At its core, SHE endeavors to describe coupled human and natural systems through showing recursive relations between societies and natural environments - both how human systems affect and are affected by their surrounding environment (Dietz \& Jorgenson, 2013; Liu et al., 2007a, 2007b; Rosa, York, \& Dietz, 2004; York et al., 2003a, 2003b). The discipline of sociology contributes insights through identifying anthropogenic drivers of ecological footprints. That is, it describes the range of human activities and societal characteristics that may affect the human imprint on the environment. This relevance for a sociological lens is especially true when combined with SHE. Research on human activities, social institutions, and relations between social units at multiple scales and across places linked with contexts, contribute to our understanding about factors affecting ecological footprints. Two important guiding principles from SHE provide a baseline for this research. First, the importance of context cannot be understated (Dietz, 2013), and the manner in which context has a particular regional flavor should be an object of investigation (Jorgenson et al., 2012). Second, the type of demographic measure incorporated into a study's design should be carefully considered and feature prominently in the empirical investigation (Marquart-Pyatt, 2013; York \& Rosa, 2012).

Incorporating these expectations refocuses the discussion about contexts to encompass societal attributes including social institutions and social structure, social organization, technology, and demographic factors in a way that extends prior work. Specifically, it adds a much-needed examination of a range of different demographic attributes to the economic and environmental dimensions that have long formed the core of this work. Essential to structural human ecology are theoretical and empirical assessments of relations among population, affluence, technology, and the environment, with environmental impacts comprising the outcome variable as in the STIRPAT model (Dietz \& Rosa, 1994, 1997). ${ }^{2}$

\footnotetext{
2 The acronym STIRPAT encapsulates Stochastic Impacts by Regression on Population, Affluence, and Technology (York, Rosa, \& Dietz, 2003a, 2003b). The baseline STIRPAT equation includes the outcome or dependent variable as the environmental impact along with an intercept term, estimated coefficients linked with population and affluence measures respectively, "technology" representing everything else in the equation, and an error term. The STIRPAT equation was designed for testing theoretically derived hypotheses from human ecology concerning the effects of population, affluence, and technology, which is now referred to as a core approach of structural human ecology (Dietz \& Jorgenson, 2013).
} 
Research utilizing the STIRPAT frame has examined numerous environmental variables approximating relations between the impacts of human societies on the environment (see Rosa \& Dietz, 2012 for a recent overview). For instance, research has explored ecological footprints and total greenhouse gas emissions as well as carbon dioxide emissions, fossil fuels, and alternative energy (Dietz \& Rosa, 1997; Dietz, Rosa, \& York, 2007, 2009; Rosa, York, \& Dietz, 2004; York, 2012; York, Rosa, \& Dietz, 2003a, 2003b). Findings from this research tradition demonstrate that population and affluence (wealth, GDP) are primary factors affecting environmental degradation (Jorgenson, 2013; Mazur, 2013).

Demographic factors feature prominently in this research. York et al. (2003a, 2003b) articulated expectations regarding how population structure influences environmental change through two key factors: the population age structure, specifically the size of a country's adult population; and a country's level of urbanization. Subsequent studies further attest to the importance of model specification, particularly in relation to the manner in which population measures are incorporated in empirical analyses, as stressed throughout STIRPAT research. As an example, York and Rosa (2012) explore nuances of population in examining how social structures and air pollution are related. Findings reveal that in addition to population size and growth, the distribution of population across households is important for understanding relations between population and the environment (York \& Rosa, 2012).

\section{West Africa as context}

The question of whether the factors driving sustainability are the same over time within West Africa, as derived from the regional emphasis in prior work (Jorgenson, 2013), has not yet been intensively examined and thus forms a core contribution of this work. I use a dataset of five developing nations in dryland West Africa over 46 years in empirical models integrating expectations from structural human ecology. The five countries examined in this research-Burkina Faso, Ghana, Mali, Niger, and Nigeria-are geographically in the Savanna/ Sahel regions of West Africa where environmental challenges are of paramount concern. A major reason for a heightened level of concern is how cropping systems are responding to environmental challenges and development, where West Africans face important questions about how to increase crop productivity and simultaneously enhance the resilience of their cropping systems to climate change (CGIAR, 2013). As of 2013, all five countries are of medium (Ghana), high (Burkina Faso and Mali) to high-extreme (Niger and Nigeria) risk of food insecurity (Maplecroft, 2013). Understanding how demographic, economic, and ecological factors shape environmental sustainability provides timely 
information for the challenges rural and urban populations in these countries face. The next section outlines the empirical models, describing the measures utilized and analytical approach employed.

\section{Data and methods}

I employ a pooled cross-section time-series analysis of a sample of five developing nations - Burkina Faso, Ghana, Mali, Niger, and Nigeria - over a 46year time period from 1961 to 2006. The unit of analysis is the nation-year. I focus only on these five nations given the theoretical focus on environmental sustainability according to ecological footprints in Western African nations. I use a Prais-Winsten (PW) regression model with panel-corrected standard errors (Beck \& Katz, 1995, 1996, 2004), which allows for heteroscedastic disturbances that are contemporaneously correlated across panels. Due to the presence of serial correlation, I specify first-order autocorrelation (AR 1) within panels. I transform all variables via logging. I use Stata 12 for the analyses. Below I discuss the operationalization of the outcome measures and the independent variables.

\section{Outcome variables}

The outcome (dependent) variable for the first set of models investigated is the ecological footprint. In the analyses, I use country level aggregate measures of the total ecological footprint. Ecological footprints (EF) represent the land area required to support levels of consumption for an individual living in a particular geographic place (i.e., country). The EF measure incorporates various land areas required for production and consumption, for waste absorption related to energy use, and for necessary infrastructure, adjusted for biological productivity (Chambers, Simmons, \& Wackernagel, 2000; Wackernagel, Onisto, \& Bello, 1999; Wackernagel \& Rees, 1996). The data was obtained from the Global Footprint Network (Global Footprint Network, 2009). In general, core, wealthy nations like the United States tend to have large ecological footprints, while developing nations, including those in West Africa, tend to have lesser environmental imprints.

Four of the EF's six subcomponents comprise the second set of outcome measures - cropland, grazing land, carbon uptake land, and built-up land. I use country level aggregate values of these composite footprint measures in the analyses. I selected these measures given their importance in the region as drivers of environmental change. Visual inspection confirmed these four subcomponents comprise a major share of the footprint for each of the countries 
individually over the time series. ${ }^{3}$ Cropland footprints take into account arable land area required to grow all crop products for a country. Grazing land is the area necessary to support livestock, including grasslands and areas required for crop growing. Carbon uptake land is the amount of forested land required to absorb human-induced $\mathrm{CO}_{2}$ emissions. The built-up land footprint takes into account the amount of land covered by societal infrastructure like transportation, housing, and industrial areas. Data for the four subcomponents are from the same time frame (1961 to 2006) (Ewing et al., 2008).

\section{Independent variables}

The models include a measure of economic development or affluence, which has been shown to be an important influence on environmental impacts (Jorgenson, 2005, 2009; Jorgenson \& Burns, 2007a, 2007b; Jorgenson \& Rice, 2005; York et al., 2003a, 2003b). Gross domestic product (GDP) per capita is included to measure economic development. GDP per capita estimates, measured in constant 2000 international dollars, are from the World Bank (2015).

Demographic factors have also been shown to influence ecological footprints, and given expectations from SHE are integral to this empirical investigation. Given predictions of structural human ecology frameworks, three aggregate demographic measures are included in the model in addition to the total population (World Bank, 2015). To gauge urbanization, a measure of urban population as a percent of the total population of a country living in urban areas is included. Rural population density is the number of people per square kilometer of land in rural areas. The population age structure or age dependency ratio is the ratio of individuals younger than 15 and older than 64 (i.e., dependents) to individuals aged 15 to 64 years (i.e., the working age population). Previous research shows more urbanized countries have larger environmental impacts (Jorgenson, 2003, 2005; Rice, 2007; York et al., 2003a, 2003b). Two measures are included to account for environmental conditions. Land area and arable land area in hectares are from the World Bank (2015). When we examine the measures that comprise the ecological footprint individually, a different picture emerges than when we investigate them as an aggregate measure (MarquartPyatt, 2010). Teasing out these relations at the within-region level over time is thus an important extension of prior work. The focus on West African nations is unique and salient as well, building on proposed future work as articulated in the discussion and conclusion that follow.

\footnotetext{
3 For example, the per capita footprint in Burkina Faso from 2006 is 1.61 hectares (ha). Within this aggregate measure, the cropland piece is $0.91 \mathrm{ha}$, grazing land is $0.19 \mathrm{ha}$, carbon is 0.04 ha and built-up land is 0.11 ha. Combined, this is 1.25 out of the 1.61 ha. In Mali in 2006, the total ecological footprint is 1.90 ha. The four subcomponents make up 1.69 ha of this value (e.g., the cropland piece is 0.73 ha, grazing land is 0.63 ha, carbon is $0.03 \mathrm{ha}$, and built-up land is $0.05 \mathrm{ha}$ ).
} 


\section{Analyses}

Figure 1 presents the ecological footprint measures for 10 time points over the 46-year time span from 1961 to 2006 for all five countries, and includes the value for the World as a reference point. Figure 2 shows the cropland footprint for ten time points over the 46 year time span from 1961 to 2006 for all five countries, also including the World value for anchoring and to aid in interpretation. Exact years are 1961, 1965, 1970, 1975, 1980, 1985, 1990, 1995, 2000, and 2005. These data points reveal that per capita ecological footprints have changed slightly over the time period shown in Figure 1. Niger, for example, had the highest per capita ecological footprint over time of these five West African countries. It was the only one of these cases with a higher EF than the world average until the early 1980s. For these years, Ghana tended to have the lowest per capita ecological footprint of these cases, with Nigeria having similar values for these data points.

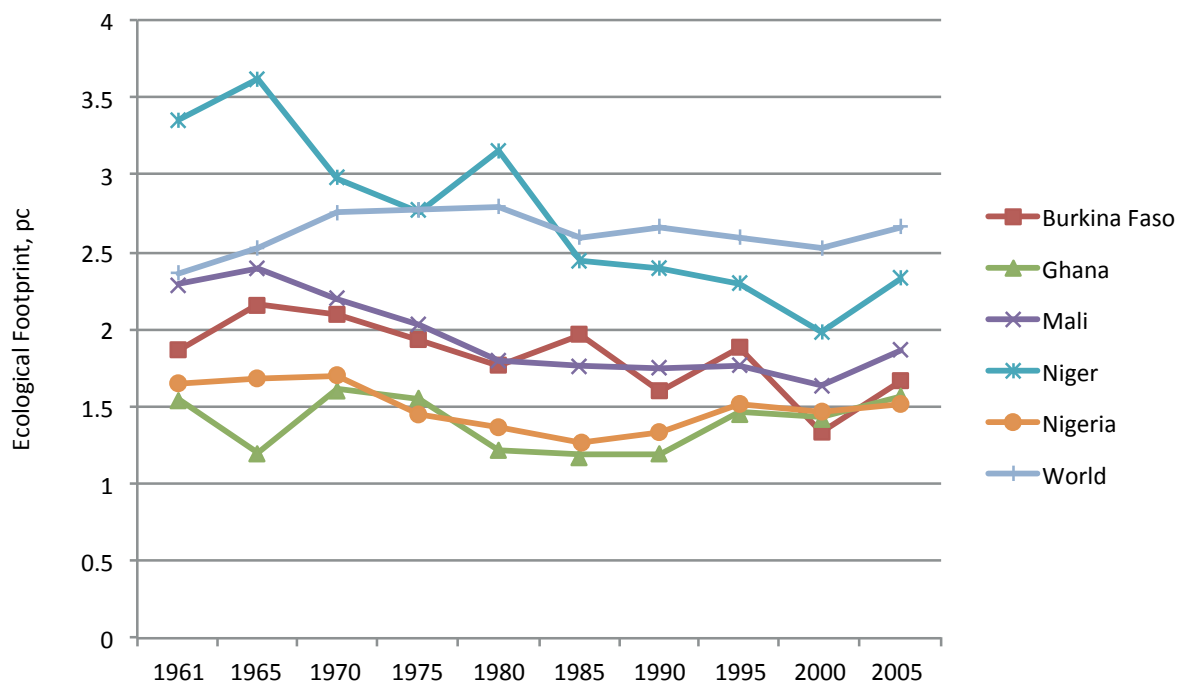

Figure 1. Per capita ecological footprint values for five countries in West Africa and the World from 1961 to 2005

Source: Global Footprint Network

Figure 2 provides a snapshot of how cropland footprints have changed over time in these five cases. Niger had the highest cropland footprint over time of these five West African countries, with a value consistently above the World average. Ghana had the lowest values for the cropland footprint of these cases for the 
time frame shown. A steady decline in the cropland footprint is only shown in the World average; otherwise, values show some variability both over time and across place (i.e., individual countries).

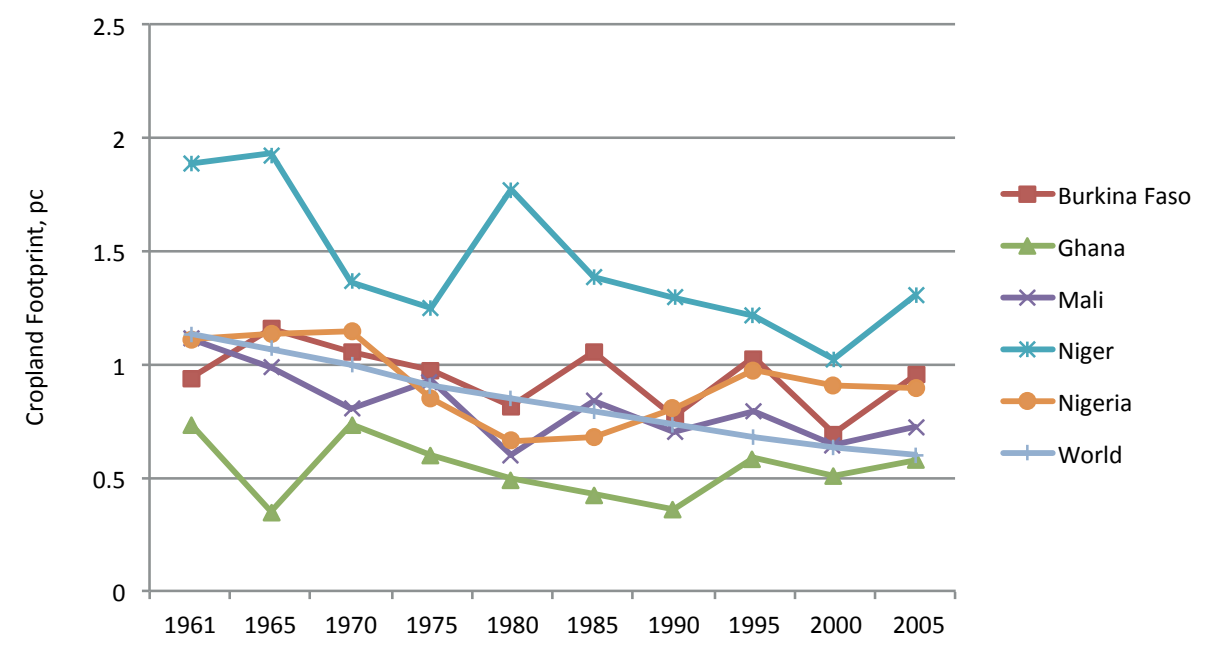

Figure 2. Per capita cropland footprint values for five countries in West Africa and the World from 1961 to 2005

Source: Global Footprint Network

Table 1 presents the descriptive statistics from the variables used in the analyses, and Tables 2 and 3 present the substantive investigation of the theoretical models. Although I include the variables according to economic, demographic, and environmental grouping of predictors, I focus on the full equation shown in model 2 of Table 2. Beginning with Table 2, although there is no significant effect for GDP, the arable land area has a positive effect on the logged ecological footprint. As shown in the third column of results, the log of urban population has a significant negative effect, where each logged percent increase in the percent of population residing in urban areas decreases the logged ecological footprint by 0.110 units. The rural population density also has a negative effect, causing a 0.270 decline in the logged ecological footprint. Combined, these results demonstrate that demographic factors, specifically the urban population and rural population density, matter for the ecological footprint in these five West African countries. 
Table 1. Descriptive statistics

\begin{tabular}{|l|c|c|c|c|c|}
\hline & Mean & Std Dev & Min & Max & N \\
\hline Total ecological footprint & 16.977 & 0.857 & 16.027 & 19.212 & 230 \\
\hline Cropland footprint & 16.249 & 0.968 & 14.804 & 18.698 & 230 \\
\hline Grazing land footprint & 14.964 & 0.836 & 13.157 & 16.362 & 230 \\
\hline Carbon-uptake footprint & 13.013 & 1.996 & 5.758 & 17.071 & 230 \\
\hline Built land footprint & 13.705 & 1.028 & 11.329 & 16.223 & 230 \\
\hline GDP $\left({ }^{*} 10,000\right)$ & 0.229 & 0.131 & 0.018 & 0.715 & 224 \\
\hline Total population & 16.379 & 0.996 & 15.0479 & 18.781 & 230 \\
\hline Percent urban & 2.999 & 0.549 & 1.758 & 3.902 & 230 \\
\hline Age dependency ratio & 4.527 & 0.077 & 4.331 & 4.661 & 230 \\
\hline Rural population density & 2.903 & 1.028 & 1.266 & 4.559 & 230 \\
\hline Land area & 0.081 & 0.080 & 0.006 & 0.379 & 230 \\
\hline Arable land & 2.365 & 0.791 & 0.851 & 3.701 & 230 \\
\hline
\end{tabular}

Table 2. Prais-Winsten regression models for total ecological footprints in West Africa, 1961-2006

\begin{tabular}{|c|c|c|}
\hline & Model 1 & Model 2 \\
\hline \multirow[t]{2}{*}{ Constant } & $36.7417^{\star \star \star}$ & $3.049^{\star \star \star}$ \\
\hline & $(8.7348)$ & $(0.911)$ \\
\hline \multirow[t]{2}{*}{ GDP } & 1136.566 & 593.305 \\
\hline & (1574.262) & $(1363.917)$ \\
\hline \multirow[t]{2}{*}{ Total population } & $1.101^{\star \star \star}$ & $0.961^{\star \star \star}$ \\
\hline & $(0.027)$ & $(0.027)$ \\
\hline \multirow[t]{2}{*}{ Percent urban } & $-0.245^{\star \star \star}$ & $-0.110^{\star \star \star}$ \\
\hline & $(0.045)$ & $(0.031)$ \\
\hline \multirow[t]{2}{*}{ Age dependency ratio } & 0.165 & -0.305 \\
\hline & $(0.306)$ & $(0.192)$ \\
\hline \multirow[t]{2}{*}{ Rural pop density } & -0.200 & $-0.270^{\star \star \star}$ \\
\hline & $(0.025)$ & $(0.046)$ \\
\hline \multirow[t]{2}{*}{ Arable land } & & $0.265^{\star \star \star}$ \\
\hline & & $(0.033)$ \\
\hline \multirow[t]{2}{*}{ Land area } & & 0.511 \\
\hline & & $(0.414)$ \\
\hline R-Square & 0.992 & 0.992 \\
\hline Sample size & 224 & 224 \\
\hline rho & 0.708 & 0.471 \\
\hline
\end{tabular}

Notes: ${ }^{\star} \mathrm{p}<.05,{ }^{\star \star} \mathrm{p}<.01,{ }^{\star \star \star} \mathrm{p}<.001$ (two-tailed) 
Table 3 shows the results from the empirical models for the cropland footprint, grazing land footprint, built land footprint, and carbon footprint, respectively. Beginning with the first column, although there is no significant effect for GDP, the arable land area has a positive effect on the logged cropland footprint. The log of urban population has a significant negative effect, where each logged percent increase in the percent of population residing in urban areas decreases the logged cropland footprint by 0.372 units. The rural population density also has a negative effect, causing a 0.323 decline in the logged cropland footprint. The second column shows findings for the grazing land footprint, revealing five significant effects. Two demographic measures cause significant declines in national ecological footprints. Urban population's effect is negative, where each logged percent increase in the percent of population residing in urban areas decreases the logged grazing land footprint by 0.424 units. The rural population density also has a negative effect, causing a 0.891 decline in the logged grazing footprint. And, the age dependency ratio has positive effects on the logged grazing footprint, while the arable land area's effect was negative.

The final two columns of results reveal the effects of economic, demographic and environmental predictors on the built land footprint and carbon footprint. Results for the built land footprint, shown in the third column of Table 3, yield slightly differing effects that make sense with regard to what this composite indicator measures. In line with previous results, the effect of urban population is negative, where each logged percent increase in the percent of population residing in urban areas decreases the logged built land footprint by 0.272 units. The rural population density has a positive effect, with a 0.501 increase in the logged built land footprint. Results in the final column are for the carbon footprint. We see a significant positive effect for GDP and negative effects for arable land area and land area on the logged carbon footprint. The log of urban population has a significant positive effect, where each logged percent increase in the percent of population residing in urban areas increases the logged carbon footprint by 1.186 units. The age dependency ratio has a significant positive effect as well, causing a 2.782 unit increase in the logged cropland footprint.

As was the case with the total EF, results suggest that demographic factors in particular matter for the cropland footprint in these five West African countries. These findings also reveal that the factors driving the different components of the ecological footprint - cropland, grazing land, built land, and carbon - differ in some regard within this set of countries. Generally, these results are in line with prior work on the ecological footprint as an aggregate measure and its constituent pieces (Marquart-Pyatt, 2010). The findings also support the work of structural human ecologists, which strives to account for complex empirical links between populations and the physical environment through extensive investigation of measures across scales, over time, and in varying contexts. 
Table 3. Prais-Winsten regression models for cropland, grazing land, built land, and carbon footprints in West Africa, 1961-2006

\begin{tabular}{|c|c|c|c|c|}
\hline & $\begin{array}{l}\text { Model 1: } \\
\text { Cropland }\end{array}$ & $\begin{array}{c}\text { Model 2: } \\
\text { Grazing Land }\end{array}$ & $\begin{array}{l}\text { Model 3: } \\
\text { Built Land }\end{array}$ & $\begin{array}{l}\text { Model 4: } \\
\text { Carbon }\end{array}$ \\
\hline \multirow[t]{2}{*}{ Constant } & $-2.952^{\star \star \star}$ & $-9.156^{\star \star}$ & -3.215 & $-25.918^{\star \star \star}$ \\
\hline & (1.610) & (3.253) & $(2.816)$ & (3.697) \\
\hline \multirow[t]{2}{*}{ GDP } & -640.275 & 1627.925 & -204.365 & $13091.200^{\star \star \star}$ \\
\hline & (2428.627) & (986.261) & (2965.38) & (2493.835) \\
\hline \multirow[t]{2}{*}{ Total population } & $1.122^{\star \star \star}$ & $1.206^{\star \star \star}$ & $1.181^{\star * *}$ & $1.454^{\star \star *}$ \\
\hline & $(0.046)$ & $(0.116)$ & $(0.063)$ & $(0.102)$ \\
\hline \multirow[t]{2}{*}{ Percent urban } & $-0.372^{\star \star \star}$ & $-0.424^{\star \star \star}$ & $-0.272^{\star \star \star}$ & $1.186^{\star \star \star}$ \\
\hline & $(0.053)$ & $(0.133)$ & $(0.088)$ & $(0.127)$ \\
\hline \multirow[t]{2}{*}{ Age dependency ratio } & 0.450 & $1.926^{\star \star \star}$ & -0.147 & $2.782^{\star \star \star}$ \\
\hline & (0.338) & $(0.590)$ & $(0.584)$ & $(0.715)$ \\
\hline \multirow[t]{2}{*}{ Rural pop density } & $-0.323^{\star \star \star}$ & $-0.891^{\star \star \star}$ & $0.501^{\star \star \star}$ & -0.088 \\
\hline & $(0.079)$ & $(0.094)$ & $(0.131)$ & $(0.153)$ \\
\hline \multirow[t]{2}{*}{ Arable land } & $0.339^{\star \star \star}$ & $-0.224^{\star \star *}$ & $-0.988^{\star \star *}$ & $-0.237 t$ \\
\hline & $(0.057)$ & $(0.103)$ & $(0.098)$ & $(0.139)$ \\
\hline \multirow[t]{2}{*}{ Land area } & 0.548 & -0.045 & -0.719 & $-6.893^{\star \star \star}$ \\
\hline & $(0.714)$ & $(0.492)$ & $(1.149)$ & $(1.182)$ \\
\hline R-Square & 0.973 & 0.971 & 0.967 & 0.873 \\
\hline Sample size & 224 & 224 & 224 & 224 \\
\hline rho & 0.415 & 0.871 & 0.692 & 0.763 \\
\hline
\end{tabular}

Notes: $t<.10,{ }^{\star} \mathrm{p}<.05,{ }^{\star *} \mathrm{p}<.01,{ }^{\star \star *} \mathrm{p}<.001$ (two-tailed)

\section{Discussion and conclusion}

This research was motivated by prior work on development that placed ensuring environmental sustainability in sharp focus for both scholars and practitioners, given its strong links with prominent international organizations. While progress has been made according to some metrics, work remains regarding realizing the global goals of achieving progress related to development and improving the well-being of individuals worldwide. Of paramount importance to this work are questions of how to model spatial and temporal variability in the environment-development link. Further, such research must include salient issues linked with quality of life like having access to clean water and sanitation, addressing climate change, and maintaining healthy ecosystems. By focusing on a single region, this research sought to contribute to this global agenda through empirical investigation of key drivers of environmental sustainability over time 
in five West African countries. Results demonstrate that, over time, national environmental imprints for this set of countries are shaped by demographic factors, supporting expectations from structural human ecology. These driving forces do differ to some extent, however, across four of the ecological footprint's subcomponents in these five nations over time.

There are at least four avenues for future work: 1) extend the analyses to examine all African countries; 2) compare this with another developing region like Southeast Asia or Latin America; 3) incorporate additional predictors like political institutions and integration in world society/polity into the model; and 4) consider how this work on EF relates with work on well-being and food security. The first two recommendations squarely focus on a core question of cross-national scholarship in sociology, namely how to construct a comparative study and what the relevant parameters are for investigation. That is, how focused or broad should the comparison be regarding the appropriate scale as well as the number of countries that comprise the relevant sample. From the five West African countries that were the focus here, future work might cast a wider net and examine all countries in Africa to determine whether these processes operate similarly across the vastly different terrestrial ecological systems on the continent. From a comparative standpoint, a second intriguing study would be one that builds a cross-regional component as a central dimension. The compelling question would then be whether the demographic factors shown to be influential in the West African context are similar to or different from how human societies and the physical environment are related in another geographically distinct region like Southeast Asia or Latin America, depending on the aspect of environmental change being investigated.

As noted above as a third recommendation, with an expanded set of cases, researchers should also consider including in the theoretical model additional predictors that derive from explanatory frameworks seeking to describe global processes of diffusion. Additional measures include a country's position in the overall world polity (like the INGO Network Country Score) (Hughes, Peterson, Harrison, \& Paxton, 2009), state environmentalism or environmental treaty participation (Roberts, Parks, \& Vasquez, 2004), and political institutions like democracy. These variables may aid in developing models that examine how being involved in different networks of relations may lead to occupying different positions in the overall world polity, where even if countries have identical numbers of INGO memberships, they may be involved in different networks that aid in explaining regional comparisons. A related measure of environmental treaty participation, which could account for engagement with international efforts for environmental protection, is also included. Additional possible measures to add to future work account for political institutions. A measure of political structure such as liberal democracy that includes both 
democratic rule and civil liberties, incorporating a country's political rights, legislative effectiveness, process of legislative selection, suffrage, and whether groups are excluded from the political process may also aid in future academic work. Resource access is likely to be tied to stratification processes like the openness of a social system to all citizens or whether restrictions are placed on natural resources and land ownership is based on citizenship rights.

Regarding extending this work beyond environmental sustainability, it is important for future work to consider the larger processes over time and across places within which these processes are embedded. Consider, for example, two related indicators of agricultural transformations describing food availability and access which provide context for understanding these issues in West Africa (FAO, 2013). Semi-arid West African countries are considered to be at mediumto-high risk of food insecurity (Maplecroft, 2013). From 1990 to 2010, food production in the region increased, with the largest gains in Ghana (from 172 to 271 international dollars per capita) and a slight increase in Burkina Faso (from 109 to 122 international dollars per capita) (FAO, 2013). At the same time, the depth of the food deficit that shows how many calories are needed to change the status of undernourished individuals, reveals declines over time in four countries, with the notable exception of an increase in Burkina Faso to 178 from 142 calories per capita daily (FAO, 2013). While some gains have been made in achieving food security, the correspondence between availability and access is not guaranteed, which has relevance for emerging work on wellbeing. Given the complexity of these issues vital for understanding the societyenvironment-development links, further refining the correspondence between our theoretical expectations and empirical models to account for variability in many forms - including temporally and spatially - remains an integral priority, fruitful avenue, and challenge for future research.

\section{References}

Beck, N., \& Katz, J. N. (1995). What to do (and not to do) with time-series crosssection data. The American Political Science Review, 89(3), 634-647.

Beck, N., \& Katz, J. N. (1996). Nuisance vs. substance: Specifying and estimating time-series-cross-section models. Political Analysis, 6, 1-36

Beck, N., \& Katz, J. N. (2004). Time-series-cross-section issues: Dynamics. Working Paper. www.nyu.edu/gsas/dept/politics/faculty/beck/beckkatz. pdf, accessed July 2015.

Bunker, S. (1985). Underdeveloping the Amazon: Extraction, Unequal Exchange, and the Failure of the Modern State. Champaign, IL: University of Illinois Press. 
CGIAR. (2013). New research approaches to improve drylands agriculture to deliver a more prosperous future. Addis Ababa, Ethiopia: CGIAR Research Program on Dryland Agricultural Production Systems.

Chambers, N., Simmons, C., \& Wackernagel, M. (2000). Sharing Nature's Interest: Using Ecological Footprints as an Indicator of Sustainability. London: Earthscan.

Dietz, T. (2013). Bringing values and deliberation to science communication. Proceedings of the National Academy of Sciences of the USA, 110, 14081-14087.

Dietz, T., \& Rosa, E. A. (1994). Rethinking the environmental impacts of population, affluence and technology. Human Ecology Review, 1, 277-300.

Dietz, T., \& Rosa, E. A. (1997). Effects of population and affluence on $\mathrm{CO}_{2}$ emissions. Proceedings of the National Academy of Sciences of the USA, 94, 175-179.

Dietz, T., Rosa, E. A., \& York, R. (2007). Driving the human ecological footprint. Frontiers in Ecology and Environment, 5(1), 13-18.

Dietz, T., Rosa, E. A., \& York, R. (2009). Environmentally efficient well-being: Rethinking sustainability as the relationship between human well-being and environmental impacts. Human Ecology Review, 16(1), 114-123.

Dietz, T., \& Jorgenson, A. (2013). Structural Human Ecology: Risk, Energy and Sustainability. Pullman, WA: Washington State University Press.

Dietz, T., \& Jorgenson, A. (2014). Towards a new view of sustainable development: Human well-being and environmental stress. Environmental Research Letters, 9(3), 031001.

Duncan, O. D. (1959). Human ecology and population studies. In P. Hauser and O. Duncan (Eds.), The Study of Population: An Inventory and Appraisal (pp. 678-716). Chicago, IL: University of Chicago Press.

Ehrhardt-Martinez, K., Crenshaw, E., \& Jenkins, J. C. (2002). Deforestation and the environmental Kuznets curve: A cross-national investigation of intervening mechanisms. Social Science Quarterly, 83, 226-243.

Ehrlich, P. R., \& Holdren, J. (1971). Impact of population growth. Science, 171, 1212-1217.

Ewing B., Reed, A., Rizk, S. M., Galli, A., Wackernagel, M., \& Kitzes, J. (2008). Calculation Methodology for the National Footprint Accounts, 2008 Edition. Oakland, CA: Global Footprint Network. 
FAO. (2013). Hunger Portal. Retrieved from www.fao.org/hunger/en/.

Global Footprint Network. (2009). The Ecological Footprint Atlas. Retrieved from www.footprintnetwork.org.

Hughes, M., Peterson, L., Harrison, J., \& Paxton, P. (2009). Power and Relation in the World Polity: The INGO Network Country Score 1978-1998. Social Forces, 87(4) 1711-1742.

Jorgenson, A. (2003). Consumption and environmental degradation: A crossnational analysis of the ecological footprint. Social Problems, 50, 374-394.

Jorgenson, A. (2004). Uneven processes and environmental degradation in the worldeconomy. Human Ecology Review, 11, 103-117.

Jorgenson, A. (2005). Unpacking international power and the ecological footprints of nations: A quantitative cross-national study. Sociological Perspectives, 48(3), 383-402.

Jorgenson, A. (2009). The sociology of unequal exchange in ecological context: A panel study of lower income countries, 1975-2000. Sociological Forum, $22,22-46$.

Jorgenson, A. (2013). Population, affluence and greenhouse gas emissions: The continuing significance of structural human ecology and the utility of STIRPAT. In T. Dietz and A. Jorgenson (Eds.), Structural Human Ecology: Risk, Energy and Sustainability (pp. 139-158). Pullman, WA: Washington State University Press.

Jorgenson, A., \& Burns, T. (2007a). The political-economic causes of change in the ecological footprints of nations, 1991-2001: A quantitative investigation. Social Science Research, 36, 834-853.

Jorgenson, A., \& Burns, T. (2007b). Effects of rural and urban population dynamics and national development on deforestation in less-developed countries, 1990-2000. Sociological Inquiry, 77(3), 460-482.

Jorgenson, A., \& Clark, B. (2011). Societies consuming nature: A panel study of the ecological footprints of nations, 1960-2003. Social Science Research, 40, 226-244.

Jorgenson, A., \& Rice, J. (2005). Structural dynamics of international trade andmaterial consumption: A cross-national study of the ecological footprints of less-developed countries. Journal of World-Systems Research, 11, 57-77. 
Jorgenson, A., Rice, J., \& Clark, B. (2012). Assessing the temporal and regional differences in the relationships between infant and child mortality and urban slum prevalence in less developed countries in less-developed countries, 1990-2005. Urban Studies, 49(16), 3495-3512.

Knight, K., Rosa, E., \& Schor, J. (2013). Could working less reduce pressures on the environment? A cross-national panel analysis of OECD countries, 1970-2007. Global Environmental Change, 23, 691-700.

Liu, J., Dietz, T., Carpenter, S. R., Alberti, M., Folke, C., Moran, E., Pell, A. N., Deadman, P., Kratz, T., Lubchenco, J., Ostrom, E., Ouyang, Z., Provencher, W., Redman, C. L., Schneider, S. H., \& Taylor, W. W. (2007a). Complexity of coupled human and natural systems. Science, 317, 1513-1516.

Liu, J., Dietz, T., Carpenter, S. R., Folke, C., Alberti, M., Redman, C. L., Schneider, S. H., Ostrom, E., Pell, A. N., Lubchenco, J., Taylor, W. W., Ouyang, Z., Deadman, P., Kratz, T., \& Provencher, W. (2007b). Coupled human and natural systems. AMBIO, 36, 639-649.

Maplecroft. (2013). 'Arab Awakening' countries at increased risk from 2013 food price shocks. Retrieved from maplecroft.com/about/news/food_security_ risk_index_2013.html.

Marquart-Pyatt, S. T. (2010). Environmental sustainability: A closer look the factors influencing national ecological footprints. International Journal of Sociology, 40(2), 65-84.

Marquart-Pyatt, S. T. (2013). The implications of structural human ecology for environmental concern's global reach. In T. Dietz \& A. Jorgenson (Eds.), Structural Human Ecology: Risk, Energy and Sustainability (pp. 159-186). Pullman, WA: Washington State University Press.

Mazur, A. (2013). Energy and electricity in industrial nations. In T. Dietz \& A. Jorgenson (Eds.), Structural Human Ecology: Risk, Energy and Sustainability, (pp. 121-138). Pullman,WA: Washington State University Press.

Rice, J. (2007). Ecological unequal exchange: International trade and unevenutilization of environmental space in the world system. Social Forces, 85, 1369-1392.

Rice, J. \& Rice, J. (2009). The concentration of disadvantage and the rise of an urban penalty: Urban slum prevalence and the social production of health inequalities in the developing countries. International Journal of Health Services, 39, 749-770. 
Roberts, J. T., Parks, B., \& Vasquez, A. (2004). Who ratifies environmental treaties and why? Institutionalism, structuralism, and participation by 192 nations in 22 treaties. Global Environmental Politics, 4(3), 22-64.

Rosa, E., \& Dietz, T. M. (2012). Human drivers of national greenhouse gas emissions. Nature Climate Change, 2, 581-586.

Rosa, E. A., York, R., \& Dietz, T. (2004). Tracking the anthropogenic drivers of ecological impacts. AMBIO: A Journal of the Human Environment, 33(8), $509-512$.

Snyder, D., \& Kick, E. (1979). Structural position in the world system and economic growth, 1955-1970: A multiple-network analysis of transnational interaction. American Journal of Sociology, 84, 1096-1126.

UNDP (United Nations Development Programme). (2014). Sustaining Human Progress: Reducing Vulnerabilities and Building Resilience (2014 Human Development Report). New York, NY: United Nations Development Programme.

Wackernagel, M., Onisto, L., \& Bello, P. (1999). National natural capital accounting with the ecological footprint concept. Ecological Economics, 29, 375-390.

Wackernagel, M., \& Rees, W. (1996). Our Ecological Footprint: Reducing Human Impact on the Earth. Gabriola Island, BC, Canada: New Society Publishers.

Wallerstein, I. (1979). The Capitalist World-Economy. Oxford: Cambridge University Press.

World Bank. (2014). World Development Report 2014: Managing Risk. Washington, DC: International Bank for Reconstruction and Development, The World Bank.

World Bank. (2015). World Development Report 2015: Mind, Society and Behavior. Washington, DC: International Bank for Reconstruction and Development, The World Bank.

York, R. (2012). Asymmetric effects of economic growth and decline on $\mathrm{CO}_{2}$ emissions. Nature Climate Change, 2(11), 762-764.

York, R., \& Rosa, E. A. (2012). Choking on Modernity: A Human Ecology of Air Pollution. Social Problems 59(2), 282-300.

York, R., Rosa, E. A, \& Dietz, T. (2003a.) Footprints on the earth: The environmental consequences of modernity. American Sociological Review, 68, 279-300. 
York, R., Rosa, E. A., \& Dietz, T. (2003b). STIRPAT, IPAT and ImPACT: Analytic tools for unpacking the driving forces of environmental impacts. Ecological Economics, 46, 351-356.

York, R., Rosa, E. A., \& Dietz, T. (2009). A tale of contrasting trends: Three measures of the ecological footprint in China, India, Japan, and the United States, 1961-2003. Journal of World-Systems Research, 15, 134-146. 
This text is taken from Human Ecology Review, Volume 22, Number 1, 2015, published 2015 by ANU Press, The Australian National University, Canberra, Australia. 